\title{
Circulating Levels of Soluble Fas Ligand in Cachexic Patients with COPD are higher than those in Non-Cachexic Patients with COPD
}

\author{
Noriaki Takabatake, Tsuyoshi Arao, Makoto Sata, Sumito InOue, \\ Shuichi ABE, Yoko ShIBATA and Isao KubotA
}

\begin{abstract}
Objective Apoptosis may be involved in the pathophysiology of cachexia in patients with chronic obstructive pulmonary disease (COPD). The purpose of this study is to assess the potential role of the Fas-Fas ligand (FasL) system in cachexic patients with COPD.

Patients and Methods We measured the circulating levels of soluble FasL (sFasL), with a newly developed, highly sensitive enzyme-linked immunosorbent assay system in seventy patients with COPD and forty-seven control subjects.

Results The levels of $\mathbf{S F a s L}$ in the COPD patients were significantly lower than those in the control subjects $(46 \pm 29$ vs. $55 \pm 28 \mathrm{pg} / \mathrm{ml} ; \mathbf{p}<0.05)$, whereas the levels of soluble Fas (sFas) remained unchanged between the two groups. The significant correlation between the levels of sFasL and sFas, observed in the control subjects $(r=0.304 ; p<0.05)$, was absent in the COPD patients. Cachexic COPD patients with a relatively lower BMI $\left(\right.$ BMI $\left.<20 \mathrm{~kg} / \mathrm{m}^{2}, \mathrm{n}=\mathbf{4 5}\right)$ and \%fat (\%fat $\left.<20 \%, \mathrm{n}=34\right)$, showed significantly increased levels of sFasL compared to non-cachexic COPD patients with a relatively higher BMI (BMI $\left.\geq 20 \mathrm{~kg} / \mathrm{m}^{2}, \mathrm{n}=25\right)$ and $\%$ fat (\% fat $\geq 20 \%$, $\mathrm{n}=36$ ) (BMI; $51 \pm 33$ vs. $36 \pm 15 \mathrm{pg} / \mathrm{ml}$; $\mathrm{p}<0.05$. \% fat; $55 \pm 33$ vs. $37 \pm 21 \mathrm{pg} / \mathrm{ml} ; \mathbf{p}<0.01$ ), due to the inverse relationships between the body composition measurements and the levels of sFasL observed exclusively in the patients (BMI; $r=-0.307 ; p<0.05$. \% fat; $r=-0.283 ; p<0.05$ ).

Conclusion These results may suggest that the FasFasL system does not play a significant role in the potential triggers of enhanced apoptosis leading to skeletal muscle wasting and adipose tissue depletion in cachexic patients with COPD.
\end{abstract}

(Internal Medicine 44: 1137-1143, 2005)
Key words: apoptosis, Fas-Fas ligand system, cachexia, COPD

\section{Introduction}

Unexplained weight loss (pulmonary cachexia) has been recognized as an important feature in advanced chronic obstructive pulmonary disease (COPD), which contributes to symptoms and influences prognosis (1). This is clinically relevant since it limits their exercise capacity, jeopardizes their quality of life, and is related to their poor prognosis, independent of the impairment in lung function $(2,3)$. Similar to the cachexia in other chronic inflammatory disorders, weight loss in patients with COPD is associated with skeletal muscle wasting and adipose tissue depletion $(4,5)$. As for the underlying mechanisms, skeletal muscle apoptosis, programmed cell death, has recently been reported as a potential process of muscle atrophy in COPD (6). In addition, there is now growing evidence that decreases in adipose tissue mass in humans could result from a loss of fat cells through apoptosis (7). Fat cell apoptosis was demonstrated in patients with tumor cachexia (8), and in human immunodeficiency virus patients (9). However, the potential trigger leading to these apoptosis, ultimately to the disruption of the homeostatic regulation involving cell death mechanisms in cachexic patients with COPD, are not fully understood.

We have previously reported that circulating levels of soluble Fas ligand (sFasL) and soluble Fas (sFas) in patients with COPD were comparable with those of the control subjects, and no relationships were observed between the circulating levels of these molecules and clinical parameters (10). However, the majority of the circulating sFasL levels of the subjects analyzed in the previous study were below the lower

From the First Department of Internal Medicine, Yamagata University School of Medicine, Yamagata

Received for publication April 19, 2005; Accepted for publication July 13, 2005

Reprint requests should be addressed to Dr. Noriaki Takabatake, the First Department of Internal Medicine, Yamagata University School of Medicine, 2-2-2 Iida-Nishi, Yamagata 990-9585 
limit of detection, because of the insufficiency of the detectability of the assay system used in the previous study (the lower limit of detection is $0.1 \mathrm{ng} / \mathrm{ml}$ in serum). In the present study, we measured circulating sFasL levels with a newly developed, highly sensitive enzyme-linked immunosorbent assay (ELISA) system (the lower limit of detection is $5 \mathrm{pg} / \mathrm{ml}$ in serum), with a larger number of patients. We also analyzed the relationships between the circulating levels of sFasL and body composition measurements in the study population, in order to demonstrate the linkage between the activation of the Fas-FasL system and tissue depletion in patients with COPD. Investigating these two points may provide insight into the relationship between the pathophysiology of the cachexia and FasL-induced apoptosis over body compartments in patients with COPD.

\section{Materials and Methods}

\section{Study population}

Seventy male patients with COPD were diagnosed according to the criteria established by the American Thoracic Society (11). Their irreversible chronic airflow obstruction was confirmed by spirogram. The patients had been clinically stable for at least 3 months and lacked clinical signs of exacerbation. Patients who had conditions known to affect serum sFasL levels, such as infection, heart failure, malignant diseases, were strictly excluded (12-14). The patients were not receiving any nutritional support therapy.

Forty-seven age-matched healthy male volunteers were studied as control subjects. These control subjects had no medical illnesses, had normal physical examinations, peripheral blood counts, blood chemistries, and showed no symptoms or signs of infection at the time of study.

After an overnight fast, all subjects had anthropometric measurements and were tested for body composition using bioelectrical impedance analysis with an instrument and software from the Omron Corporation (HBF-301; Tokyo, Japan) (5). The study protocol was approved by the local ethical committee of Yamagata University School of Medicine, and the written informed consent was obtained from all subjects before participating in this study.

\section{Pulmonary function test}

$\mathrm{FVC}$ and $\mathrm{FEV}_{1.0}$ were measured with standard spirometric techniques (CHESTAC-25 part II EX; Chest Corp., Tokyo, Japan). The highest value from at least three spirometric maneuvers was used. Reference values were those proposed by the Japanese Society of Chest Diseases (15). Arterial blood gas was analyzed with the subject breathing room air in the sitting position (280 Blood Gas System; Ciba Corning Diagnostics Corp., Medfield, MA).

\section{Measurement of serum sFasL levels}

Serum sFasL levels were measured with a newly developed, highly sensitive ELISA system (16). In brief, two monoclonal antibodies against human FasL, F918-20-2 and
F919-9-18, were prepared previously. Microtiter plates were coated with antihuman FasL antibody (F918-20-2 F(ab')2). Sera samples were added to the wells. The purified human recombinant FasL produced in pichia pastoris was used as a standard. After incubation for 2 hours at $37^{\circ} \mathrm{C}$, the wells were washed with saline containing $0.05 \%$ Tween 20 . The wells were incubated with polyclonal peroxidase labeled antihuman FasL antibody F919-9-18 for 1 hour at $37^{\circ} \mathrm{C}$, and washed with saline containing $0.05 \%$ Tween 20 and distilled water. The wells were incubated with tetramethylbenzidine (TMB) for 20 minutes. Peroxidase activity was developed in proportion to the amount of sFasL. The reaction was stopped by adding $1 \mathrm{~N} \mathrm{H}_{2} \mathrm{SO}_{4}$. The color generated was determined by measuring the $\mathrm{OD}$ at $450 \mathrm{~nm}$ in a spectrophotometric microtiter plate reader (model 450; Bio-Rad, Richmond, CA). The limit of detection (negative control, $0 \mathrm{pg} / \mathrm{ml}+2 \mathrm{SD}$ ) was 5 $\mathrm{pg} / \mathrm{ml}$. Intra- and interassay coefficients of variation (CVs) were $<2.4$ to $11.7 \%$ and $<8.3$ to $15.7 \%$, respectively. We performed all assays in duplicate, and the mean of two sets of data was determined for each individual sample.

\section{Measurement of serum sFas levels}

Serum sFas levels were also measured by a sandwich ELISA kit (Medical \& Biological Laboratories Co., Ltd, Nagoya, Japan) (16). This ELISA kit is capable of detecting the secretory form of sFas (not the proteolytic membrane form). The sensitivity for serum sFas is $0.5 \mathrm{ng} / \mathrm{ml}$, according to the manufacturer. We performed all assays in duplicate, and the mean of two sets of data was determined for each individual sample.

\section{Statistical analysis}

Because the normality hypothesis was not always fulfilled for most of the variables, statistical analysis was performed with the Mann-Whitney's U test for nonparametric data to analyze the differences between the two groups. The relations between continuous variables were evaluated by Spearman's rank correlations. Results were expressed as mean \pm SD. Significance was determined at the 5\% level. Statistical analysis was done using the Statview Statistical Package (Statview, Inc., Berkeley, CA).

\section{Results}

\section{Characteristics of the study population}

Clinical characteristics of both the COPD patients and the healthy controls are shown in Table 1. Patients with COPD had a significantly lower body weight (BW), body mass index (BMI) and percent body fat (\%fat) compared with the control subjects. The present COPD patients were associated with severe airflow limitation, decreased arterial $\mathrm{pO}_{2}$ and increased arterial $\mathrm{pCO}_{2}$. Control subjects had normal values on spirogram. 
Highly Sensitive sFasL and COPD Cachexia

Table 1. Study Population

\begin{tabular}{lccc}
\hline & COPD patients $(\mathrm{n}=70)$ & Control subjects $(\mathrm{n}=47)$ & $\mathrm{p}$-value* \\
\hline Age $(\mathrm{yr})$ & $72.3 \pm 7.2$ & $71.8 \pm 7.4$ & $\mathrm{NS}$ \\
Height $(\mathrm{m})$ & $1.60 \pm 0.05$ & $1.63 \pm 0.07$ & $\mathrm{p}<0.01$ \\
Body weight $(\mathrm{kg})$ & $49.2 \pm 10.1$ & $60.3 \pm 9.3$ & $\mathrm{p}<0.0001$ \\
BMI $\left(\mathrm{kg} / \mathrm{m}^{2}\right)$ & $19.3 \pm 3.7$ & $22.8 \pm 2.4$ & $\mathrm{p}<0.0001$ \\
\%fat $(\%)$ & $20.5 \pm 6.8$ & $23.6 \pm 4.4$ & $\mathrm{p}<0.05$ \\
VC $(l)$ & $2.31 \pm 0.80$ & $3.45 \pm 0.83$ & $\mathrm{p}<0.0001$ \\
$\% \mathrm{VC}(\%)$ & $73.7 \pm 23.6$ & $106.6 \pm 21.8$ & $\mathrm{p}<0.0001$ \\
FEV $(l)$ & $0.92 \pm 0.46$ & $2.61 \pm 0.67$ & $\mathrm{p}<0.0001$ \\
\%FEV & $44.9 \pm 20.3$ & $119.4 \pm 21.0$ & $\mathrm{p}<0.0001$ \\
FEV $_{1.0} / \mathrm{FVC}(\%)$ & $73.7 \pm 12.5$ & $89.5 \pm 5.0$ & $\mathrm{p}<0.0001$ \\
Arterial $\mathrm{PO}_{2}(\mathrm{mmHg})$ & $63.4 \pm 11.8$ & $42.3 \pm 2.9$ & $\mathrm{p}<0.0001$ \\
Arterial $_{\mathrm{PCO}}(\mathrm{mmHg})$ & $47.4 \pm 8.7$ & $\mathrm{p}<0.001$ \\
\hline
\end{tabular}

Values are presented as mean \pm SD. *Mann-whitney $U$ test. NS: not significant.

\section{Circulating levels of sFasL and sFas of the study population}

We first analyzed serum sFasL and sFas levels in patients with COPD and in the healthy controls. The levels of sFasL in the COPD patients was significantly lower than those in the healthy controls $(46 \pm 29$ vs. $55 \pm 28 \mathrm{pg} / \mathrm{ml} ; \mathrm{p}<0.05$, Fig. 1A). There was no significant difference in the levels of sFas between the COPD patients and the healthy controls (2.33 \pm 0.84 vs. $2.13 \pm 0.62 \mathrm{ng} / \mathrm{ml}$; p=NS, Fig. 1B). We found a significant positive correlation between serum sFasL and sFas levels in the control subjects $(r=0.304 ; p<0.05$, Fig. 2A), whereas this correlation was not observed in the COPD patients (Fig. 2B).

\section{Relationships between sFasL levels and the body composition measurements of the study population}

We evaluated the relationships between the levels of sFasL and the body composition measurements in both groups, to demonstrate the linkage between the activation of the Fas-FasL system and weight loss and/or tissue depletion in patients with COPD. There were significant inverse relationships between the levels of sFasL and BMI $(r=-0.307$; p $<0.05$, Fig. 3B) as well as \%fat $(r=-0.283$; $p<0.05$, Fig. 4B) in patients with COPD. In contrast, these significant relationships were not observed in the control subjects (Figs. 3A and $4 \mathrm{~A}$, respectively). There were no significant correlations between the levels of sFasL and any other clinical parameters of the severity of COPD in patient groups. Neither serum sFasL levels of the control group, nor sFas levels in both groups, showed significant correlations with the clinical parameters.

In order to confirm the relationships between the levels of sFasL and BMI as well as \%fat in patients with COPD, we divided the COPD patients into two subgroups according to the cut-off index of each reference value, respectively (6, 17). Patients in a subgroup with a relatively lower BMI (BMI $<20 \mathrm{~kg} / \mathrm{m}^{2}, \mathrm{n}=45$, cachexic patients) showed significantly increased levels of sFasL compared to those in a subgroup with a relatively higher BMI (BMI $\geq 20 \mathrm{~kg} / \mathrm{m}^{2}, \mathrm{n}=25$, noncachexic patients) $(51 \pm 33$ vs. $36 \pm 15 \mathrm{pg} / \mathrm{ml} ; \mathrm{p}<0.05$, Fig. $5 \mathrm{~A})$. Similarly, patients in a subgroup with a relatively lower $\%$ fat (\%fat $<20 \%, n=34$, cachexic patients) showed significantly increased levels of sFasL than those in a subgroup with a relatively higher \%fat (\%fat $\geq 20 \%, n=36$, noncachexic patients) $(55 \pm 33$ vs. $37 \pm 21$ pg/ml; p $<0.01$, Fig. 5 B $)$.

\section{Discussion}

Fas ligand (FasL) is a $40-\mathrm{kD}$ type II transmenbrane protein that is homologous to tumor necrosis factor- $\alpha$ (TNF- $\alpha$ ) (18). FasL induces apoptosis by binding to its membrane receptor Fas (CD95) through the activation of caspases, leading to proteolysis of vital cellular constituents (18). Although the expression of FasL was originally considered restricted to activated T cells and NK cells, FasL has been identified in other cell types such as Sertoli cells, corneal cells, myoblasts, vascular endothelial cells, and tumors $(19,20)$. As long as the Fas-FasL system is appropriately expressed, the system will be indispensable for maintaining homeostasis. However, if the system under- or overfunctions, it could be detrimental. When this system overfunctions, it causes tissue destruction. The tissue disintegrations by FasL-induced apoptosis, such as hepatitis, insulin-dependent diabetes, and chronic thyroiditis, have been demonstrated (18). Membrane-bound FasL can be cleaved to become a soluble form by a metalloproteinase-like enzyme (21). sFasL induces apoptosis (22), although the ability of inducing apoptosis may be more potent in membrane-bound FasL than sFasL (23). On the other hand, sFas, generated from a variety of cell types by alternative mRNA splicing, blocks apoptosis in cells by inhibiting the binding of FasL to Fas on the cell membrane $(24,25)$. Elevated circulating levels of sFasL and its relation to the disease activity have been reported in other chronic disorders such as congestive heart failure and 

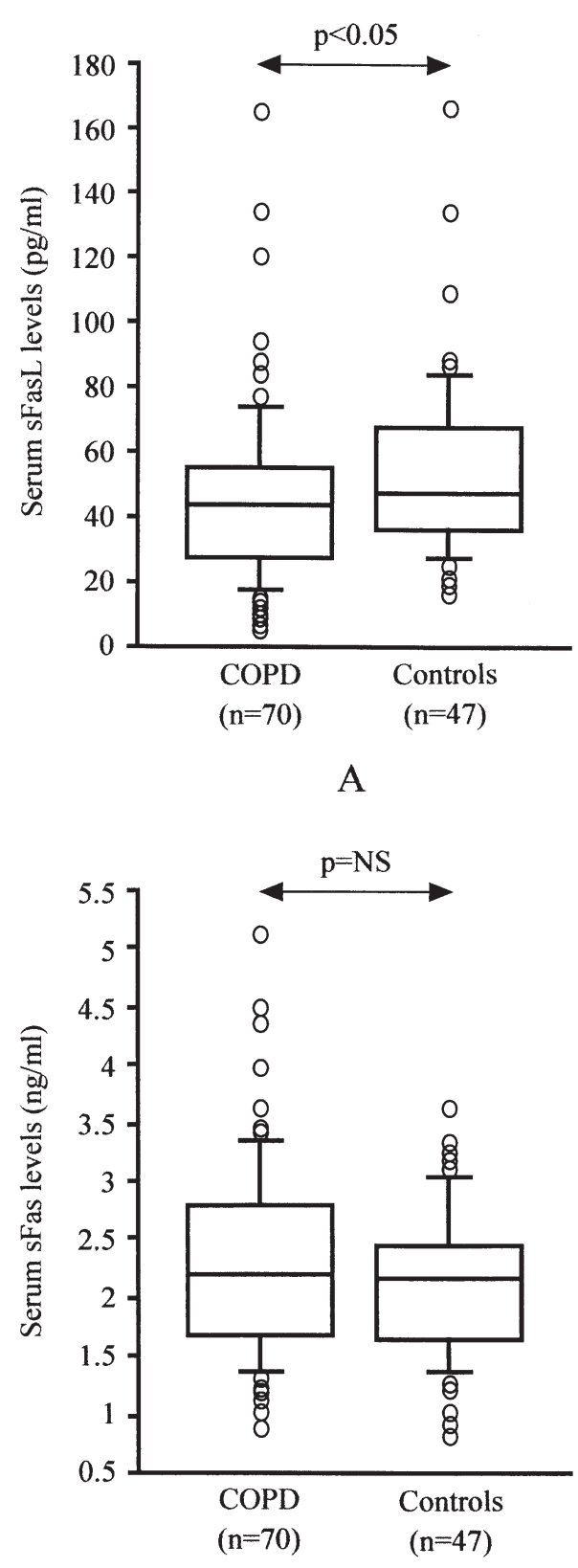

B

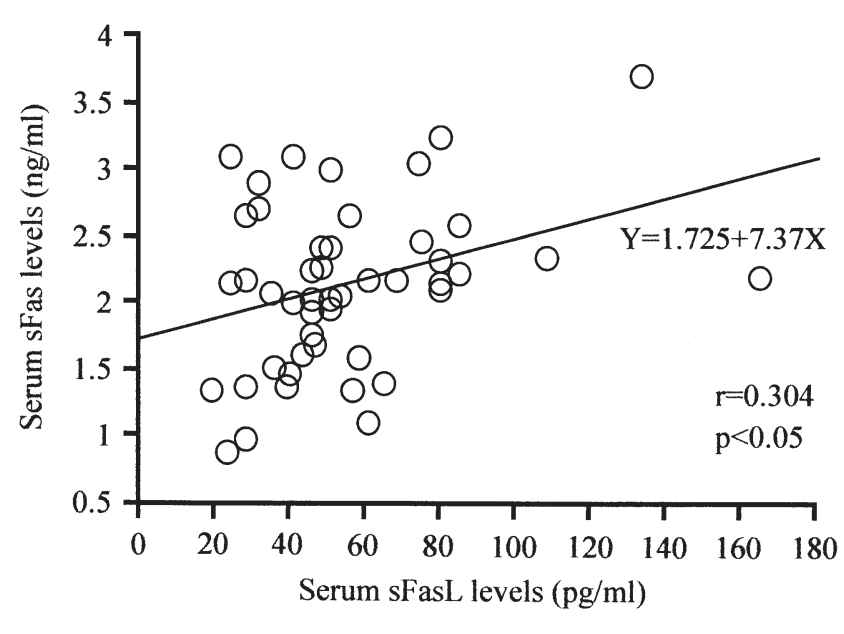

A) Controls

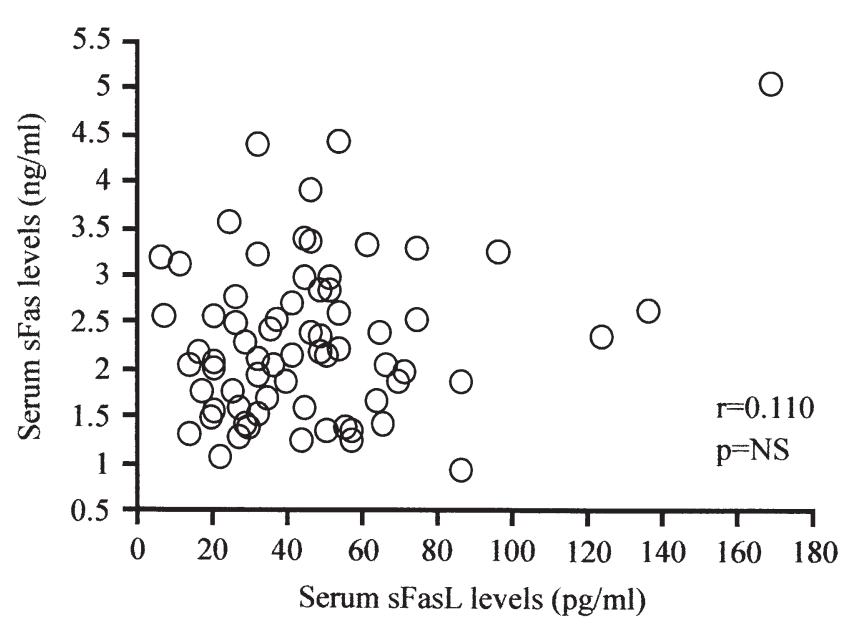

B) COPD

Figure 2. The relationships between serum sFasL levels and serum sFas levels in the control subjects (A) and in patients with COPD (B). NS: not significant.

apoptosis, remained unchanged between the two groups. The significant correlation between the levels of sFasL and sFas, observed in the control subjects, was lost in patients with COPD. In addition, the COPD patients with lower BMI and $\%$ fat (cachexic patients) showed elevated levels of sFasL compared with the non-cachexic patients with COPD, due to the inverse relationships between the body composition measurements and the levels of sFasL observed exclusively in patients with COPD. There were no relationships between the levels of sFasL and the parameters of lung function test in patients with COPD. Although the apoptosis is reported to be an important mechanism in the pathogenesis of alveolar epithelial and vascular endothelial cell death of emphysematous lungs (27-30), the results of this study, as a whole, may indicate that the Fas-FasL system does not play a significant 


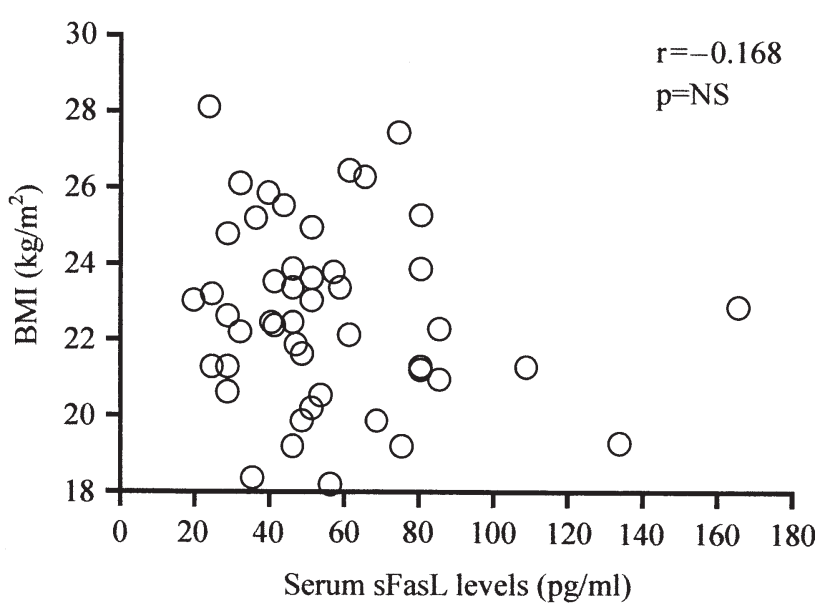

A) Controls

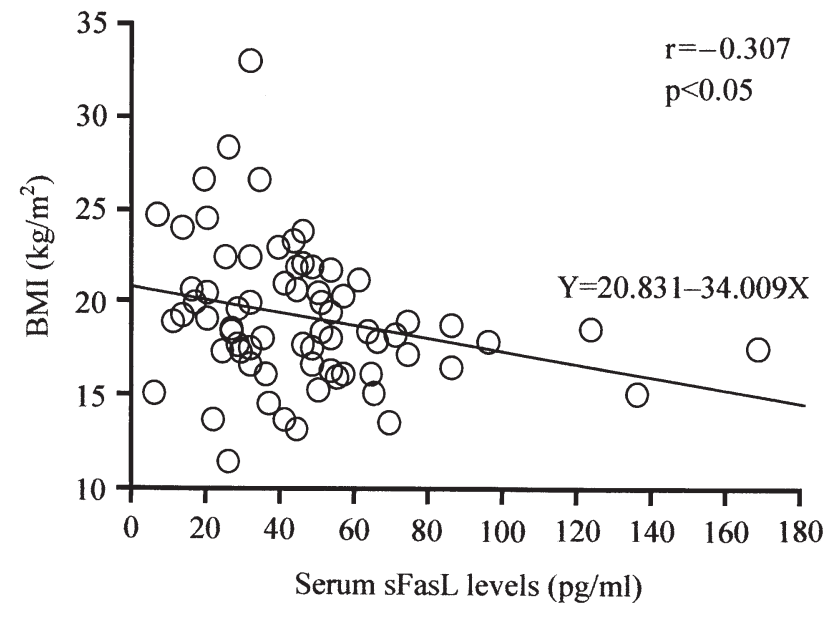

B) COPD

Figure 3. The relationships between serum sFasL levels and BMI in the control subjects (A) and in patients with COPD (B). NS: not significant.

role in the potential triggers of enhanced apoptosis in skeletal muscle, and in the adipose tissue depletion in cachexic patients with COPD.

In the present study, circulating levels of sFasL in the control group $(55 \pm 28 \mathrm{pg} / \mathrm{ml})$ were comparable to the reported sFasL values of control subjects in other studies (60 to $90 \mathrm{pg} / \mathrm{ml})(12,13,31)$. The slightly lower levels of sFasL in our control group compared with the reported values in other studies is explicable from the fact that a significant negative correlation exists between age and circulating levels of sFasL in healthy subjects (14), and that the mean age of our control group was over 70 year, the highest age among those of the control subjects in other studies. Also, it is interesting that the circulating levels of sFasL were not high in all cachexic patients with COPD, and that wide distribution of

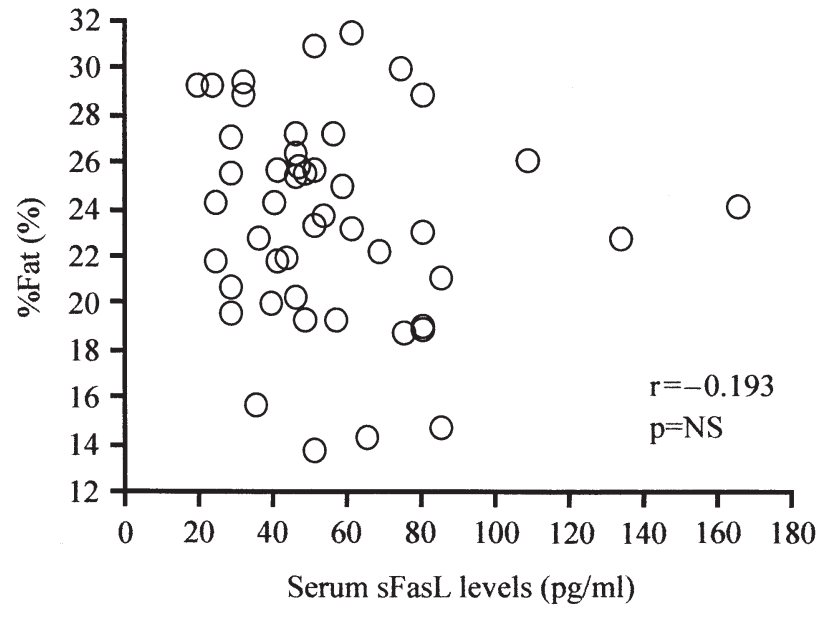

A) Controls

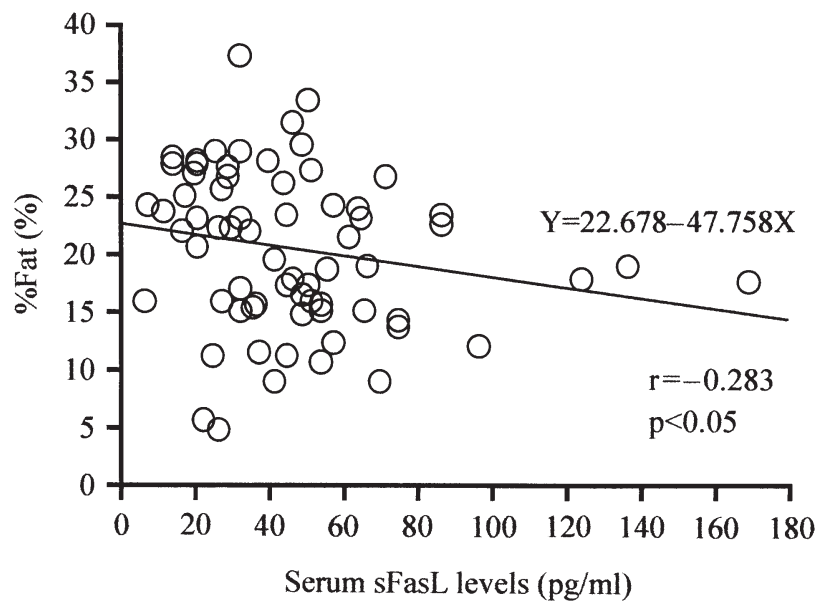

B) COPD

Figure 4. The relationships between serum sFasL levels and $\%$ fat in the control subjects (A) and in patients with COPD (B). NS: not significant.

the levels of sFasL was observed in cachexic patients with COPD compared with the non-cachexic patients with COPD. Although the Fas-FasL system does not appear to play an important role in the potential triggers of enhanced apoptosis in skeletal muscle and the adipose tissue in cachexic patients with COPD as a whole, it may be possible that the Fas-FasL system might be activated for a period of the deterioration of emaciation of COPD, whereas the Fas-FasL system might be silent during the period of stable state even in the presence of cachexia in patients with COPD.

The main cellular source of the expression and secretion of FasL into the systemic circulation is unknown. Peripheral blood T-lymphocytes may be speculated, since these lymphocytes are known to produce the functional forms of sFasL, and inappropriate activation of these lymphocytes has 


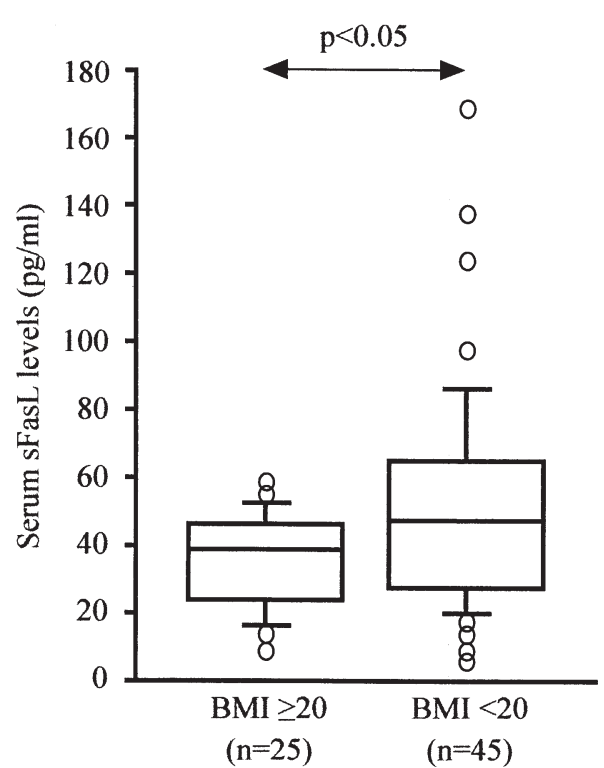

A

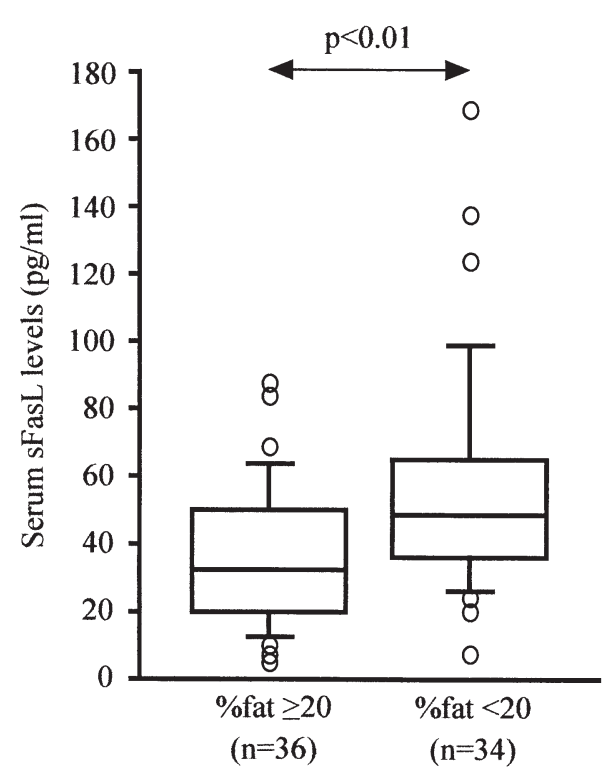

B

Figure 5. Box plot of serum sFasL levels in COPD patients with relatively higher $(n=25$, non-cachexic patients) and lower $(n=45$, cachexic patients) BMI (A), and with relatively higher $(n=36$, non-cachexic patients) and lower $(n=34$, cachexic patients) $\%$ fat (B). Twenty $\mathrm{kg} / \mathrm{m}^{2}$ (BMI) and percent (\% fat) as cut-off indices are based on the reference values (see text).

been suggested in patients with COPD (32). However, the behavior of the Fas-FasL system in the systemic circulation in COPD patients, demonstrated in this study, does not necessarily reflect those at local sites (i.e., skeletal muscle and adipose tissue), especially since myoblasts have been reported to express FasL per se (19).
In summary, using a newly developed, highly sensitive ELISA system, we demonstrated that the circulating levels of sFasL in patients with COPD were significantly reduced compared to those of the control subjects, whereas the levels of sFas remained unchanged between the two groups. The significant correlation between the levels of sFasL and sFas, observed in the control subjects, was absent in patients with COPD. Also, the cachexic patients with COPD showed elevated levels of sFasL compared with the non-cachexic patients with COPD, due to the inverse relationships between the body composition measurements and the circulating levels of sFasL observed exclusively in patients with COPD. Overall, the results of this study may suggest that the FasFasL system does not play a significant role in the potential triggers of enhanced apoptosis leading to skeletal muscle wasting and adipose tissue depletion through uncontrolled signaling pathways of apoptosis in cachexic patients with COPD. However, we believe that it is of great clinical and scientific interest to attempt to clarify the potential role of the Fas-FasL system at local sites (i.e., skeletal muscle and adipose tissue), for a better understanding of cachexia commonly seen in patients with COPD.

Acknowledgements: This study was supported by a grant-in-aid from the 21 st century Center Of Excellence (COE) program of the Japan Society for the Promotion of Science, and was supported in part by grants-in-aid for Scientific Research from the Ministry of Education, Culture, Sports, Science and Technology, Japan (Nos. 15790407 and 15590796).

\section{References}

1) Schols AM. Pulmonary cachexia. Int J Cardiol 85: 101-110, 2002.

2) Schols AM, Slangen J, Volovics L, Wouters EF. Weight loss is a reversible factor in the prognosis of chronic obstructive pulmonary disease. Am J Respir Crit Care Med 157: 1791-1797, 1998.

3) Landbo C, Prescott E, Lange P, Vestbo J, Almdal TP. Prognostic value of nutritional status in chronic obstructive pulmonary disease. Am J Respir Crit Care Med 160: 1856-1861, 1999.

4) Debigare R, Cote $\mathrm{CH}$, Maltais F. Peripheral muscle wasting in chronic obstructive pulmonary disease: clinical relevance and mechanisms. Am J Respir Crit Care Med 164: 1712-1717, 2001.

5) Takabatake N, Nakamura $\mathrm{H}$, Abe $\mathrm{S}$, et al. Circulating leptin in patients with chronic obstructive pulmonary disease. Am J Respir Crit Care Med 159: 1215-1219, 1999.

6) Agusti AG, Sauleda J, Miralles C, et al. Skeletal muscle apoptosis and weight loss in chronic obstructive pulmonary disease. Am J Respir Crit Care Med 166: 485-489, 2002.

7) Fischer-Posovszky P, Tornqvist H, Debatin KM, Wabitsch M. Inhibition of death-receptor mediated apoptosis in human adipocytes by the insulin-like growth factor I (IGF-I)/IGF-I receptor autocrine circuit. Endocrinology 145: 1849-1859, 2004.

8) Prins JB, Walker NI, Winterford CM, Cameron DP. Human adipocyte apoptosis occurs in malignancy. Biochem Biophys Res Commun 205: 625-630, 1994.

9) Domingo P, Matias-Guiu X, Pujol RM, et al. Subcutaneous adipocyte apoptosis in HIV-1 protease inhibitor-associated lipodystrophy. AIDS 13: 2261-2267, 1999.

10) Takabatake N, Nakamura $H$, Inoue $S$, et al. Circulating levels of soluble Fas ligand and soluble Fas in patients with chronic obstructive pulmonary disease. Respir Med 94: 1215-1220, 2000.

11) American Thoracic Society. Standards for the diagnosis and care of 


\section{Highly Sensitive sFasL and COPD Cachexia}

patients with chronic obstructive pulmonary disease. Am J Respir Crit Care Med 152: S77-S121, 1995.

12) Yamaguchi $S$, Yamaoka $M$, Okuyama $M$, et al. Elevated circulating levels and cardiac secretion of soluble Fas ligand in patients with congestive heart failure. Am J Cardiol 83: 1500-1503, 1999.

13) Bahr GM, Capron A, Dewulf J, et al. Elevated serum level of Fas ligand correlates with the asymptomatic stage of human immunodeficiency virus infection. Blood 90: 896-898, 1997.

14) Ichikura T, Majima $T$, Uchida $T$, Okura E, Ogawa $T$, Mochizuki $H$. Plasma soluble Fas ligand concentration: decrease in elderly men and increase in patients with gastric carcinoma. Oncol Rep 8: 311-314, 2001.

15) Japanese Society of Chest Disease. Standards of pulmonary function tests for Japanese. Jpn J Thorac Dis 31: appendix, 1993.

16) Kuwano K, Kawasaki M, Maeyama T, et al. Soluble form of fas and fas ligand in BAL fluid from patients with pulmonary fibrosis and bronchiolitis obliterans organizing pneumonia. Chest 118: 451-458, 2000.

17) Takabatake N, Nakamura H, Minamihaba O, et al. A novel pathophysiologic phenomenon in cachexic patients with chronic obstructive pulmonary disease: the relationship between the circadian rhythm of circulating leptin and the very low-frequency component of heart rate variability. Am J Respir Crit Care Med 163: 1314-1319, 2001.

18) Nagata S. Apoptosis by death factor. Cell 88: 355-365, 1997.

19) Kang SM, Hoffmann A, Le D, Springer ML, Stock PG, Blau HM. Immune response and myoblasts that express Fas ligand. Science 278: 1322-1324, 1997.

20) Sata M, Walsh K. TNFalpha regulation of Fas ligand expression on the vascular endothelium modulates leukocyte extravasation. Nat Med 4: 415-420, 1998.

21) Kayagaki N, Kawasaki A, Ebata T, et al. Metalloproteinase-mediated release of human Fas ligand. J Exp Med 182: 1777-1783, 1995.

22) Tanaka M, Suda T, Takahashi T, Nagata S. Expression of the functional soluble form of human fas ligand in activated lymphocytes.
EMBO J 14: 1129-1135, 1995.

23) Suda $T$, Hashimoto $H$, Tanaka M, Ochi $T$, Nagata $S$. Membrane Fas ligand kills human peripheral blood $\mathrm{T}$ lymphocytes, and soluble Fas ligand blocks the killing. J Exp Med 186: 2045-2050, 1997.

24) Cheng J, Zhou T, Liu C, et al. Protection from Fas-mediated apoptosis by a soluble form of the Fas molecule. Science 263: 1759-1762, 1994.

25) Cascino I, Fiucci G, Papoff G, Ruberti G. Three functional soluble forms of the human apoptosis-inducing Fas molecule are produced by alternative splicing. J Immunol 154: 2706-2713, 1995.

26) Kuwano K, Maeyama T, Inoshima I, et al. Increased circulating levels of soluble Fas ligand are correlated with disease activity in patients with fibrosing lung diseases. Respirology 7: 15-21, 2002.

27) Aoshiba K, Yokohori N, Nagai A. Alveolar wall apoptosis causes lung destruction and emphysematous changes. Am J Respir Cell Mol Biol 28: 555-562, 2003.

28) Yokohori N, Aoshiba K, Nagai A; Respiratory Failure Research Group in Japan. Increased levels of cell death and proliferation in alveolar wall cells in patients with pulmonary emphysema. Chest 125: 626-632, 2004.

29) Kasahara Y, Tuder RM, Cool CD, Lynch DA, Flores SC, Voelkel NF. Endothelial cell death and decreased expression of vascular endothelial growth factor and vascular endothelial growth factor receptor 2 in emphysema. Am J Respir Crit Care Med 163: 737-744. 2001.

30) Arao T, Takabatake N, Sata M, et al. In vivo evidence of endothelial injury in chronic obstructive pulmonary disease by lung scintigraphic assessment of (123)I-metaiodobenzylguanidine. J Nucl Med 44: 17471754, 2003.

31) Taieb J, Mathurin P, Poynard T, Gougerot-Pocidalo MA, CholletMartin S. Raised plasma soluble Fas and Fas-ligand in alcoholic liver disease. Lancet 351: 1930-1931, 1998.

32) Takabatake N, Sata M, Abe S, et al. Impaired systemic cell-mediated immunity and increased susceptibility to acute respiratory tract infections in patients with COPD. Respir Med 99: 485-492, 2005. 